\title{
ANAEMIA IN HYPOTHYROIDISM: A SINGLE CENTRE STUDY
}

\author{
Smita Das ${ }^{1}$, B. P. Chakravarty 2 \\ ${ }_{1}^{1}$ Assistant Professor, Department of Clinical Haematology, Gauhati Medical College and Hospital. \\ 2 Professor, Department of Medicine, Gauhati Medical College and Hospital.
}

\section{ABSTRACT}

\section{BACKGROUND}

Anaemia is frequently associated with hypothyroidism. This study was conducted to study the prevalence and types of anaemia in primary hypothyroidism along with its various clinical manifestations.

\section{METHODS}

In this retrospective study, out of the 120 patients with primary hypothyroidism, 50 that were found to be suffering from anaemia were evaluated for the type most prevalently associated with hypothyroidism considering various clinical manifestations and laboratory investigations. This was carried out in a tertiary care teaching hospital.

\section{RESULTS}

Among 120 patients, 50 were detected to have anaemia with a prevalence of $41.66 \%$ [95\% Confidence Interval: $0.32-0.51$ ]. Of whom 44 were females (51.11\%) and 6 males (17.64\%). 23 (46\%) patients had normocytic normochromic anaemia, 19 (38\%) patients had microcytic hypochromic anaemia and $8(16 \%)$ patients had macrocytic anaemia. The most common clinical symptoms suggestive of anaemia in hypothyroidism were easy fatigability (100\%). Pallor was seen in all 50 patients (100\%). The mean Hb level in the study group was $7.34 \mathrm{~g} / \mathrm{dL}$ with a range $6.2-8.5 \mathrm{~g} / \mathrm{dL}$. The mean reticulocyte count (Corrected) was found to be $0.92 \%$ in all types of anaemia. The mean S. ferritin level was found to be low $(11.45 \mathrm{mcg} / \mathrm{dL})$ only in those with microcytic hypochromic anaemia. The study revealed 3 patterns of bone marrow picture namely normocellular, erythroid hyperplasia and hypercellular marrow.

\section{CONCLUSIONS}

Anaemia in hypothyroidism is a common association and most commonly presented with easy fatigability and decreased appetite. Normocytic normochromic anaemia constituted the most common type of anaemia in hypothyroidism.

\section{KEYWORDS}

Hypothyroidism- Anaemia- Normocytic Normochromic.

HOW TO CITE THIS ARTICLE: Das S, Chakravarty BP. Anaemia in hypothyroidism: a single centre study. J. Evolution Med. Dent. Sci. 2016;5(36):2138-2141, DOI: 10.14260/jemds/2016/499

\section{INTRODUCTION}

Hypothyroidism results from insufficient production of thyroid hormones and anaemia is fairly common in hypothyroidism.(1,2) Hypothyroidism induced decreased metabolism can lead to decreased tissue need for oxygen as an adaptation to hypometabolic state leading to inadequate erythropoietin stimulation resulting in anaemia.(3-5) In addition, malabsorption or nutritional deficiencies of iron, vitamin B12 and folate in hypothyroid state can aggravate or contribute to existing anaemia.(5-8) The aim is to study the prevalence and types of anaemia in primary hypothyroidism along with its various clinical manifestations.

\section{METHODS}

A total of 120 patients with primary hypothyroidism were selected for the study. Of them, 50 patients were diagnosed with anaemia. Clinical data on detailed history and thorough clinical examination including signs and symptoms of anaemia and hypothyroid state and complications were recorded.

Financial or Other, Competing Interest: None.

Submission 11-02-2016, Peer Review 22-03-2016,

Acceptance 28-03-2016, Published 05-05-2016.

Corresponding Author:

Dr. Smita Das,

Department of Clinical Haematology,

Gauhati Medical College Hospital,

Guwahati-781032.

E-mail: smitabhuyanghy@gmail.com

DOI: 10.14260/jemds/2016/499
All patients of either sex, above the age of 18 years with signs and symptoms suggestive of hypothyroidism and anaemia were included in the study. Patients with secondary causes of hypothyroidism and with other concomitant systemic illness, gastrointestinal bleed or with exposure to cytotoxic drugs were excluded.

The demographic pattern, types of anaemia, clinical presentations and nutritional status was investigated.

Routine investigations including Complete Haemogram, Peripheral Blood Smear (PBS), Reticulocyte Count, Iron Profile, Liver Function Test (LFT), Renal Function Test (RFT), estimation of thyroid hormone (T3, T4 and TSH) and Anti-TPO was done in all 50 cases. DCT, HPLC, Serum Vitamin B12, Folic acid, Stool for occult blood, Bone Marrow Aspiration (BMA) Study, Upper Gastrointestinal endoscopies, Colonoscopy examination and Ultrasound examination of the Thyroid Gland and Abdomen were done in selected patients.

Hospital Ethical Committee accorded permission for the study.

\section{RESULTS AND OBSERVATIONS}

In this study, 50 patients out of 120 patients were detected to have anaemia. The prevalence of anaemia was $41.66 \%$. There was female preponderance with male:female ratio of 3:22 in this study.

In this study, the most common clinical symptoms suggestive of anaemia in hypothyroidism that the patients came with were Easy fatigability $(100 \%)$, Loss of appetite (78\%), Muscle cramp (62\%), Dyspnoea (56\%), Palpitation 
(50\%), Weight gain (42\%), Menorrhagia (34\%), Paraesthesia (28\%) and oedema (16\%). The distribution of clinical symptoms has been shown in the following table in order of decreased frequency Table 1.

The most common clinical signs, which could be elicited on physical examination of the studied patients in order of increasing frequency were pallor of the mucous membrane that was seen in all 50 patients (100\%), alopecia in $28(56 \%)$, hypertension in 25 (50\%), oedema in 15 (30\%), poor nutrition in $9(18 \%)$, hepatomegaly in $8(16 \%)$ and splenomegaly in 5 (10\%) Table 2.

In this study, it was found that 3 different types of anaemia were prevalent in the study group. Among them, the most common anaemia was found to be normocytic normochromic anaemia (46\%). It was followed by microcytic hypochromic anaemia (38\%), which was caused mainly due to iron deficiency as found to be associated with menorrhagia, poor nutritional status and increased demand. Decreased absorption and dietary deficiency were found to be the cause of macrocytic anaemia (16\%) (Figure 1).

The distribution of various types of anaemia among the male population showed $66.66 \%$ with normocytic normochromic anaemia and $33.34 \%$ with macrocytic anaemia. No cases were found to have microcytic hypochromic anaemia. Among the female population, equal incidences of normocytic normochromic anaemia and microcytic anaemia were found with incidence of $38 \%$ and macrocytic anaemia showed an incidence of $12 \%$.

The combined mean $\mathrm{Hb}$ level in the study group was 7.34 $\mathrm{g} / \mathrm{dL}$. In the study, $74 \%$ had $\mathrm{Hb}$ level in the range $7-10 \mathrm{~g} / \mathrm{dL}$ (Moderate anaemia), 26\% had $\mathrm{Hb}$ level in the range below 7 $\mathrm{g} / \mathrm{dL}$ (Severe anaemia). None of the patients had Hb above 10 $\mathrm{g} / \mathrm{dL}$ (Mild anaemia). Therefore, most patients were found to be suffering from moderate anaemia in this study (Figure 2).

In the study, the mean reticulocyte count (Corrected) was found to be $0.92 \%$ in all types of anaemia. In normocytic normochromic anaemia it was $0.8 \%$, in microcytic hypochromic anaemia it was $1.1 \%$ and in macrocytic anaemia $0.88 \%$.

The combined mean S. iron level in the study group was $32.1 \mathrm{microg} / \mathrm{dL}$. In the study, $56 \%$ had S. iron level below the normal range suggesting iron deficiency anaemia, where the mean S. iron level was found to be $26.26 \mathrm{micro} / \mathrm{dL}$ and $44 \%$ had S. iron level in the normal range suggesting secondary effect of hypothyroid state, where the mean S. iron level was found to be 37.94 microg/dL. None of the patients had S. iron level more than the upper normal.

The mean S. TIBC level was found to be $373.13 \mathrm{mcg} / \mathrm{dL}$ in normocytic normochromic anaemia, $435.47 \mathrm{mcg} / \mathrm{dL}$ in microcytic hypochromic anaemia and $373.8 \mathrm{mcg} / \mathrm{dL}$ in macrocytic anaemia.

The mean transferrin saturation level was found to be below normal at $9.3 \%$ in normocytic normochromic anaemia, $6.5 \%$ in microcytic hypochromic anaemia and $14.3 \%$ in macrocytic anaemia.

The mean S. ferritin level was found to be $34.69 \mathrm{mcg} / \mathrm{dL}$ in normocytic normochromic anaemia, $11.4 \mathrm{mcg} / \mathrm{dL}$ in microcytic hypochromic anaemia and $30.66 \mathrm{mcg} / \mathrm{dL}$ in macrocytic anaemia.

In the study, it was found that the most common cause of iron deficiency anaemia was probably due to increased loss of blood as in case of menorrhagia seen in $34 \%$, followed by dietary deficiency as assessed by the poor nutritional status seen in $18 \%$ and increased demand as in pregnancy seen in $36 \%$. Combined or multiple effects of various factors was found from history, clinical findings and investigations in $23 \%$. Three patients gave history of becoming oligomenorrheic after a period of an average of 2-3 yrs. of menorrhagia.

Out of the 17 patients that had menorrhagia, except 1 all others had iron deficiency anaemia.

Vitamin B12, folic acid estimation level, low levels of both Vitamin B12 (mean 195 pg/mL), folic acid (mean $1.9 \mathrm{ng} / \mathrm{mL}$ ) in 2 patients.

In the study population, patients with haemoglobinopathy were in 5 out of $50(10 \%)$. Out of them, 1 patient had $\mathrm{HbE}$ disease and the rest 4 had $\mathrm{HbE}$ trait.

The range of TSH level was correlated with the mean $\mathrm{Hb}$ level in each range to ascertain whether the severity of the thyroid status led to increased severity of anaemia. In the study, $14 \%$ with subclinical hypothyroidism (TSH level of 4-10 miu/L) had mean Hb level of $7.3 \mathrm{~g} / \mathrm{dL}, 32 \%$ with TSH level of 11-20 miu/L had mean $\mathrm{Hb}$ level of $7.18 \mathrm{~g} / \mathrm{dL}, 12 \%$ with TSH level of 21-30 miu/L had mean $\mathrm{Hb}$ level of $7.33 \mathrm{~g} / \mathrm{dL}, 6 \%$ with TSH level of 31-40 miu/L had mean Hb level of $7.03 \mathrm{~g} / \mathrm{dL}, 2 \%$ with TSH level of 41-50 miu/L had mean Hb level of $8.4 \mathrm{~g} / \mathrm{dL}$ $8 \%$ with TSH level of 51-60 miu/L had mean Hb level of 6.9 $\mathrm{g} / \mathrm{dL}, 6 \%$ with TSH level of 61-70 miu/L had mean $\mathrm{Hb}$ level of $7.3 \mathrm{~g} / \mathrm{dL}$ and $20 \%$ with TSH level of more than $75 \mathrm{miu} / \mathrm{L} \mathrm{had}$ mean $\mathrm{Hb}$ level of $7.5 \mathrm{~g} / \mathrm{dL}$.

Bone marrow was done in 17 out of 50 patients in a random manner to confirm the type of anaemia and to rule out secondary causes in suspected patients and revealed 3 patterns of bone marrow picture namely normocellular, erythroid hyperplasia and hypercellular marrow. Normocellular pattern was seen in normocytic normochromic anaemic patient, erythroid hyperplasia in microcytic hypochromic and hypercellular in macrocytic patients. The M:E ratio was found to be 2:1 in all the cases (Figure 3).

\begin{tabular}{|c|c|c|c|}
\hline Sl. No. & Clinical Symptoms & $\begin{array}{c}\text { No. of } \\
\text { Patient }\end{array}$ & $\mathbf{\%}$ \\
\hline 1 & Easy fatigability & 50 & 100 \\
\hline 2 & Loss of appetite & 39 & 78 \\
\hline 3 & Muscle cramp & 31 & 62 \\
\hline 4 & Dyspnoea & 28 & 56 \\
\hline 5 & Palpitation & 25 & 50 \\
\hline 6 & Weight gain & 21 & 42 \\
\hline 7 & Menorrhagia & 17 & 34 \\
\hline 8 & Paraesthesia & 14 & 28 \\
\hline 9 & Oedema & 8 & 16 \\
\hline \multicolumn{3}{|c|}{ Table 1: Shows the Most Common Clinical Symptoms } \\
Suggestive of Anaemia in Hypothyroidism \\
\hline \multicolumn{4}{|c}{} \\
\hline
\end{tabular}

\begin{tabular}{|c|c|c|c|}
\hline Sl. No. & Clinical Signs & $\begin{array}{c}\text { No. of } \\
\text { Patient }\end{array}$ & $\mathbf{\%}$ \\
\hline 1 & Pallor & 50 & 100 \\
\hline 2 & Alopecia & 28 & 56 \\
\hline 3 & Hypertension & 25 & 50 \\
\hline 4 & Oedema & 15 & 30 \\
\hline 5 & Cardiomegaly & 10 & 20 \\
\hline 6 & Poor nutrition & 9 & 38 \\
\hline 7 & Hepatomegaly & 8 & 16 \\
\hline 8 & Splenomegaly & 5 & 10 \\
\hline \multicolumn{2}{|c|}{$\begin{array}{r}\text { Table 2: Illustrate the Most Common Clinical Signs } \\
\text { which could be elicited on Physical Examination of the } \\
\text { studied Patients in order of Decreasing Frequency }\end{array}$} \\
r
\end{tabular}




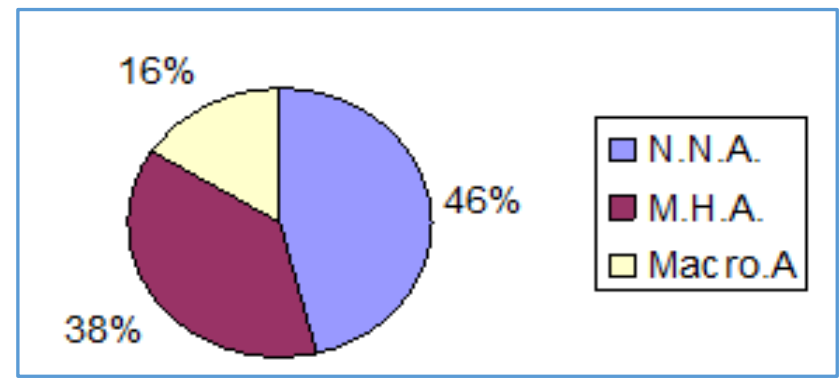

Diagram 1: Shows the Percentage Distribution of Different Types of Anaemia in Hypothyroidism in the Study Population

NNA: Normocytic Normochromic Anaemia, MHA: Microcytic Hypochromic Anaemia, Macro A: Macrocytic Anaemia

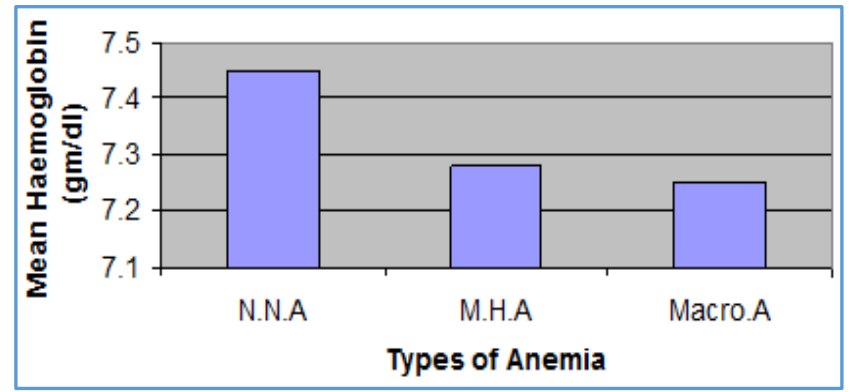

Diagram 2: Showing the Distribution of Haemoglobin Level in Different Types of Anaemia in Hypothyroidism

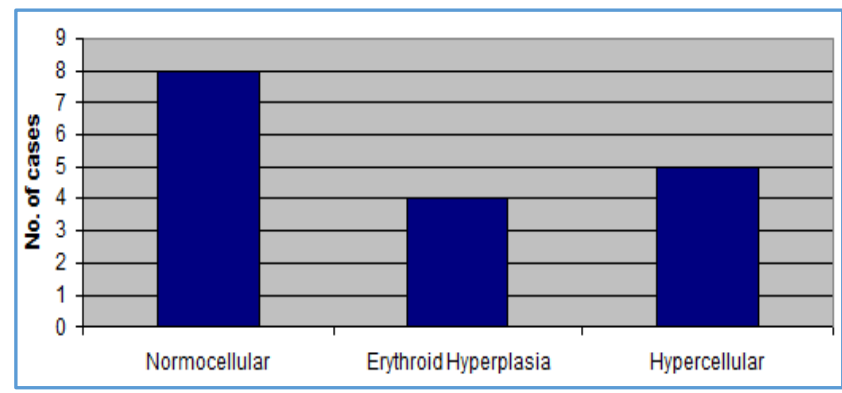

Diagram 3: Showing Different Patterns of Bone Marrow Picture in Anaemia in Hypothyroidism in the Study Population

\section{DISCUSSION}

Several studies have reported incidence of anaemia in hypothyroidism ranging from 21 to $60 \%$. $(2,9-11)$ Related studies had found incidence to lie in the range. $(2,5-8)$ This study has found to be prevalent of $41.66 \%$.

Regarding sex ratio, more females (44) than males (6) out of 50 were found to have anaemia in this study like some other studies.(5,6,12-14) contrary to another study that found more male prevalence.(2)

The present study has found normocytic normochromic anaemia (46\%) has been the most common type of anaemia. Other studies have also attributed normocytic normochromic anaemia as the most common type of anaemia in their studies, because of the primary hypothyroid status. $(2,12,13)$ As stated earlier, thyroid hormone directly or indirectly stimulates erythroid colonies (BFU-e, CFU-e). But hypothyroid state results in inadequate Erythropoietin (EPO) stimulation due to reduced tissue need for oxygen as an adaptation to hypometabolic state. In response to the diminished oxygen and decreased production of erythropoietin, RBC mass is decreased; this is evident in the mild normocytic normochromic anaemia often occurring. Anaemia due to hypothyroidism is characterized by a small decrease of the half-life of red cells, caused either by a disturbance of the iron metabolism or by resistance to erythropoietin action.(3-5,15)

The second most common type of anaemia found in the present study was Microcytic Hypochromic Anaemia (38\%). Two other studies have attributed this type of anaemia in hypothyroidism as most common. $(5,16)$ The pathogenesis of this iron deficiency is not completely clear, but may be related to menorrhagia so common in hypothyroidism or may be due to increased demand as in pregnancy and also due to dietary insufficiency. Iron deficiency to be considered in microcytic hypochromic anaemia until proved otherwise. $(2,3,8)$ In the present study, it was found that the most common cause of iron deficiency anaemia was due to increased loss of blood as in case of menorrhagia seen in $34 \%$ followed by dietary deficiency as assessed by the poor nutritional status seen in $18 \%$ and increased demand as in pregnancy seen in $6 \%$. Also iron clearance from the blood is reduced in hypothyroidism, suggesting reduced erythropoiesis. $(15,17,18)$

The least common type of anaemia found in the present study was macrocytic anaemia (16\%) and has been attributed to pernicious anaemia, decreased dietary intake and malabsorption of vit B12 and folic acid. Some studies have attributed much higher prevalence to this type of anaemia in hypothyroidism. $(2,5,12)$

Some studies. ${ }^{(19,20)}$ have stated that the degree of anaemia is related to the duration and severity of anaemia. They stated that it is probable that any patient who remains hypothyroid for a sufficiently long period will develop at least an uncomplicated anaemia. No such correlation could be elicited in this study, probably because of lower volume of plasma in hypothyroidism giving false level of haemoglobin; also associated factors like iron, folate or vitamin B12 deficiency in significant number of patients along with a small study population done over a limited period could have influenced the outcome.

The bone marrow in hypothyroidism in absence of associated deficiency of iron or vit B12 usually shows decreased cellularity and increased fat content without evidence of erythroid hyperplasia.(21,22) Present study have found normocellular pattern in normocytic normochromic anaemic patient, erythroid hyperplasia in microcytic hypochromic and hypercellular in macrocytic patients. The M:E ratio was found to be 2:1 in all the cases.

\section{CONCLUSIONS}

Anaemia in hypothyroidism is a common association and most commonly presented with easy fatigability and decreased appetite. Normocytic normochromic anaemia constituted the most common type of anaemia in hypothyroidism. However, microcytic hypochromic anaemia too was found to be of high incidence, probably due to its association with iron deficiency anaemia.

\section{REFERENCES}

1. Pearce EN, Farwell AP, Braverman LE. Thyroiditis. N Engl J Med 2003;348:2646-55.

2. Horton L, Cobura RJ, England JM, et al. The haematology of hypothyroidism. QJM 1976;45(177):101-23. 
3. Bomford R. Anaemia in myxoedema: and the role of the thyroid gland in erythropoiesis. QJM 1938;7(4):495-536.

4. Green ST, Ng JP. Hypothyroidism and anaemia. Biomed Pharmacother 1986;40(9):326-31.

5. Tudhope GR, Wilson GM. Anaemia in hypothyroidism incidence, pathogenesis, and response to treatment. QJM 1960;29:513-37.

6. Hines JD, Halsted Ch, Griggs RC, et al. Megaloblastic anaemia secondary to folate deficiency associate with hypothyroidism. Ann Intern Med 1968;68(4):792-805.

7. Mc Lean E, De Benoist B, Allen LH. Review of the magnitude of folate and vitamin B12 deficiencies worldwide. Food Nutr Bull 2008;29(2):S38-51.

8. Goldsmith RE, Sturgis Sh, Lerman J, et al. The menstrual pattern in thyroid disease. J Clin Endocrinol Metab 1952;12(7):846-55.

9. Aybike Kosenli, Mehmet Erdogan, Sencer Ganidagli, et al. Anaemia frequency and aetiology in primary hypothyroidism. Endocrine Abstracts 2009;20:140.

10. Antonijevic N, Nesovic M, Trbojevic B, et al. Anaemia in hypothyroidism, article in (Serbo-Croatian Roman). Med Pregl 1999;52(3-5):136-40.

11. Benoist B, McLean E, Egli I, et al. Global database on anaemia. Geneva: WHO; 2008. World wide prevalence of anaemia 1993-2005;pp1-2.

12. Carpenter JT, Mohler DN, Thorup OA, et al. Anaemia in myxedema, in current concepts in hypothyroidism, edited by KR Crispell. Macmillan, New York, 1963;14757.
13. Dawson MA, Yarbro JW. Anaemia in hypothyroidism. Southern Med J 1970;63(8):966-70.

14. Cinemre H, Bihi C, Gokosmanglu F, et al. Haematological effects of levothyroxine in iodine deficient subclinical hypothyroid patients: a randomized, double-blind, controlled study. The Journal of Clinical Endocrinology \& Metabolism 2009;94(1):151-6.

15. Kiely JM, Purnell DC, Owen CA. Erythrokinetics in myxoedema. Ann Intern Med 1967;67(3):533-8.

16. Larsson SO. Anaemia and iron metabolism in hypothyroidism. Acta Med Scand 1957;157:339-63.

17. Shalet M, Coe D, Reismann KR. Mechanism of erythropoietic action of thyroid hormone. Proc Soc Exp Biol Med 1966;123(2):443-6.

18. Golde DW, Berch N, Chopra IJ, et al. Thyroid hormones stimulate erythropoesis in vitro. $\mathrm{Br} \mathrm{J}$ Haemtol 1977;37(2):173-7.

19. Stern B, Altschule MD. Haematologic studies in hypothyroidism following total thyroidectomy. J Clin Invest 1936;15(6):633-41.

20. Erdogan M, Kosenli A, Sencer G, et al. Characteristics of anaemia in subclinical and overt hypothyroid patients. Endocr J 2012;59(3):213-20.

21. Axelrod AR, Berman L. The bone marrow in hyperthyroidism and hypothyroidism. Blood 1951;6(5):436-53.

22. Jones RM. Human sternal bone marrow in hyperthyroid and myxoedematous states. Am J Med Sci 1940;200:211. 